\title{
The Belgrade PaleoBlitz: A pilot project to engage amateur paleontologists
}

\author{
Victor J. Perez, Ronny M. Leder, Lisa Lundgren, \\ Shari Ellis, Betty Dunckel, and Kent Crippen
}

\begin{abstract}
Paleontology is an interdisciplinary field that attracts a range of individuals, from hobbyists to professionals. A primary goal of the NSF-funded FOSSIL Project is to establish a unified community of paleontologists and promote best practices in the field of paleontology. The Belgrade PaleoBlitz was a pilot effort to meet these goals by guiding participants through the museum curation process via a rapid two-day immersion. The objectives of the PaleoBlitz event were to: 1) educate participants in best practices associated with the museum curation process, and 2) catalog specimens collected from the Belgrade Quarry into the Florida Museum of Natural History vertebrate paleontology collections. These objectives seek to find a balance between educating participants and contributing to science. A pre-event application dispersed to amateur paleontology clubs throughout the United States determined applicants' baseline content knowledge and practices. To facilitate learning and promote networking, we selected 13 participants who varied in expertise from six different paleontology organizations. Immediate and delayed post-event surveys assessed acceptance and implementation of best practices, confidence related to specific aspects of the museum curation process, and expansion of individuals' personal paleontology network. Responses showed that all participants made changes to their existing collections, felt more confident in specific aspects of the museum curation process, and had continued connections with other participants after this event.
\end{abstract}

Victor J. Perez. Department of Vertebrate Paleontology, Florida Museum of Natural History, 1659 Museum Rd., Gainesville, FL 32611, USA and 2 Department of Geological Sciences, University of Florida, 241

Williamson Hall, PO Box 112120, Gainesville, FL 32611, USA. victorjperez@ufl.edu

Ronny M. Leder. Department of Vertebrate Paleontology, Florida Museum of Natural History, 1659

Museum Rd., Gainesville, FL 32611, USA. leder.ronnymaik@flmnh.ufl.edu

Lisa Lundgren. School of Teaching and Learning, College of Education, University of Florida, 423 Norman Hall, Gainesville, FL 32611, USA. lisa.lundgren21@gmail.com

Shari Ellis. Center for Science Learning, Florida Museum of Natural History, University of Florida,

Gainesville, FL 32611, USA. sellis@flmnh.ufl.edu

Perez, Victor J., Leder, Ronny M., Lundgren, Lisa, Ellis, Shari, Dunckel, Betty, and Crippen, Kent. 2020. The Belgrade PaleoBlitz: A pilot project to engage amateur paleontologists. Palaeontologia Electronica, 23(1):a18. https://doi.org/10.26879/1013 palaeo-electronica.org/content/2020/3009-paleontology-citizen-science 
Betty Dunckel. Center for Science Learning, Florida Museum of Natural History, University of Florida, Gainesville, FL 32611, USA. badunckel@gmail.com

Kent Crippen. School of Teaching and Learning, College of Education, University of Florida, 423 Norman Hall, Gainesville, FL 32611, USA. kcrippen@coe.ufl.edu

Keywords: citizen science; outreach; fossil clubs; museum curation; bioblitz

Submission: 26 July 2019. Acceptance: 6 April 2020.

\section{INTRODUCTION}

Paleontology is a natural history discipline in which its practitioners range from hobbyists to professionals. These stakeholder groups have been classically perceived as dichotomous, with professionals being research oriented and amateurs being collection oriented (Crippen et al., 2016; MacFadden et al., 2016). This dichotomy was driven by conflicting interests and disagreements related to ethics of fossil collecting (e.g., Robbins, 2009; Bixby, 2014), and possibly exacerbated by professional arrogance. However, this dichotomy is an antiquated perception, as by definition the only thing that distinguishes professionals from amateurs is compensation for their work. Amateur, or avocational, paleontologists span the gambit of citizen science participation-from serendipitous fossil discoveries (e.g., Godfrey, 2015) to leading advanced research (e.g., Kallmeyer and Ausich, 2015). Many amateurs have expertise on par with that of professionals, well-curated collections with elegant exhibits akin to museums, and collaborate within clubs and societies. That said, with such a wide range of involvement in the practice of paleontology, many practitioners are unaware of appropriate best practices. In order to advance the field of paleontology, it is important to provide educational events that promote best practices and continued participation. To ensure effective intervention, it is also critical to understand how educational events affect participants, which is a primary goal of the NSF-funded (DRL-1322725) FOSSIL Project (Fostering Opportunities for Synergistic STEM with Informal Learners). The PaleoBlitz led participants through the entire museum curation process and facilitated learning through a cognitive apprenticeship (Collins, 2006), in which more experienced participants help guide less experienced participants through this process.

Natural history fields-such as ornithology, herpetology, and forest ecology - that deal with living organisms have employed programs referred to as BioBlitzes, during which groups of people record species occurrences in specific regions over a relatively short period of time (Lundmark, 2003; Karns et al., 2006). Susan Rudy, a naturalist affiliated with the U.S. National Parks Service, hosted the first recorded BioBlitz at the Kenilworth Park and Aquatic Gardens in Washington D.C. (USGS, 1996). Generally, BioBlitzes are short events, taking place in 24 hours or less, produce of an inventory of all living organisms within a specific geographic region, and involve both amateurs and professionals. Amateurs gain experience in proper field techniques, exposure to scientific terminology and taxonomy, and practice in identification, while often contributing to research and conservation efforts in their own local communities. Professionals benefit from increased public awareness and support of their science, while collecting extensive data that would otherwise be impossible to gather alone.

An example of the BioBlitz concept being applied to the field of paleontology was the Jurassic FossilBlitz, during which roughly 200 participants reported fossil species abundance data over a six-hour period at Monmouth Beach in southern England (Twitchett, 2015). Individuals and family groups chose $50 \times 50 \mathrm{~cm}^{2}$ quadrants at random and used identification charts to identify and record every fossil observed within their respective quadrants. In total, they sampled 87 quadrants, resulting in more than 1600 fossil occurrences (Twitchett et al., 2015). This sample is an order of magnitude larger than that of a similar study conducted by Pugh et al. (2015) from the same area. From two specific geologic units referred to as Beds 29 and 31 , the FossilBlitz covered 69 quadrants, producing 1084 occurrences; from the same two beds, Pugh et al. (2015) sampled four quadrants and reported 79 occurrences (Twitchett et al., 2015).

This manner of partnership between professional and amateur paleontologists is not unprecedented (e.g., the University of Florida Hummingbird Challenge in 2013). During this event, amateurs contribute to fossil excavations and screenwashing matrix at a historic locality, Thomas Farm, over a weekend stint. Events such as these stimulate 
interest in paleontology, expand basic content knowledge, and make major contributions to field collections. However, paleontology is more than collecting and identifying; rather it is an extended process involving collection, preparation (i.e., cleaning), identification, documentation (i.e., photographing), and curation (i.e., organizing, typically in a database). Others have extended the blitz concept in interesting ways. The National Parks Service first coined the term PaleoBlitz in reference to a 10-year effort to document all the fossil occurrences in the U.S. National Parks (Santucci et al., 2012). The Natural History Museum of Los Angeles County hosted a series of DigiBlitzes, during which a group of professionals rapidly catalogued large quantities of invertebrate fossils to reduce the backlog of material and advance the research potential of the collection (Hendy, personal communication, 2016).

Each of the aforementioned events focuses on one or two aspects of the museum curation process; however, to optimize contributions to the field of paleontology, all practitioners should be well versed in the best practices associated with every stage of the curatorial process: Collection - Preparation - Identification - Documentation - Curation. Crippen et al. (2016) found that a majority of amateur paleontologists (94\% of respondents) are interested in face-to-face meetings that incorporate practical workshops about how to identify and catalog fossils, and a majority of professional paleontologists $(88 \%$ of respondents) believe that properly trained amateurs could contribute to the digitization of fossil specimens. The Belgrade PaleoBlitz aimed to provide participants with a rapid immersion into the entire museum curatorial process, while gaining a better understanding of what motivates individuals and supports their continued participation in paleontology. As such, the three primary goals of this event were:

\section{Promote Best Practices:}

Educate participants about the entire museum curation process, from recording field data to digitizing and curating a collection.

\section{Support the Practice:}

Support the practice of paleontology by understanding what motivates participation in paleontology, increasing confidence in paleontology methods, and expanding participants' personal network of paleontologists.

\section{Refine PaleoBlitz Design:}

Refine the structure of the PaleoBlitz through participant feedback and staff observations.

\section{METHODS}

\section{PaleoBlitz Design}

In March 2015, FOSSIL Project staff joined a group of professional and amateur collectors to collect the spoil piles in the Belgrade Quarry operated by Martin Marietta in Maysville, North Carolina. The Special Friends of the Aurora Museum, an amateur fossil organization, organized this trip as a thank you to those who were volunteering at the Aurora Fossil Festival the following day. This collaborative collecting effort included professionals from the Smithsonian Institution (NMNH) and the Florida Museum of Natural History (FLMNH) and amateurs from the North Carolina Fossil Club and the Southwest Florida Fossil Society among others, and resulted in thousands of fossil specimens collected. The specimens collected offer broad research potential given the variable ages of the fossils and the limited accessibility of the site. The Belgrade Quarry has fossils of Oligocene to Pleistocene age, including both marine and terrestrial taxa, much of which is contemporaneous with well-documented deposits in Florida (Richards, 1950). Given the potential research significance and the abundance of fossil material, members of the FOSSIL Project decided to host a workshop in which amateur paleontologists could participate in the museum curation process using the Belgrade material.

Dissemination of the announcement for the PaleoBlitz event occurred through Facebook, Twitter, myfossil.org, email, and face-to-face communication. The FOSSIL Project incentivized participation by covering the cost of lodging and some meals; however, participants had to pay for their travel and other meals. Prior to the event, selected participants joined the myFOSSIL community and initiated conversations about their PaleoBlitz expectations on an online forum within myFOSSIL.

The Belgrade PaleoBlitz was devised and implemented as a two-day event, providing a rapid immersion into the museum curation process (Figure 1). The first hour and a half was an informal meet and greet, as well as an introduction to what the program would entail. Each participant received a packet including a schedule, identification guides, and a recent publication on the fossil sharks and rays of the Gainesville creeks (Boyd, 2016). This introduction also included a guided tour of the FOSSIL Project's website, myfossil.org, which serves as a centralized hub of paleontological information and resources for improving the 

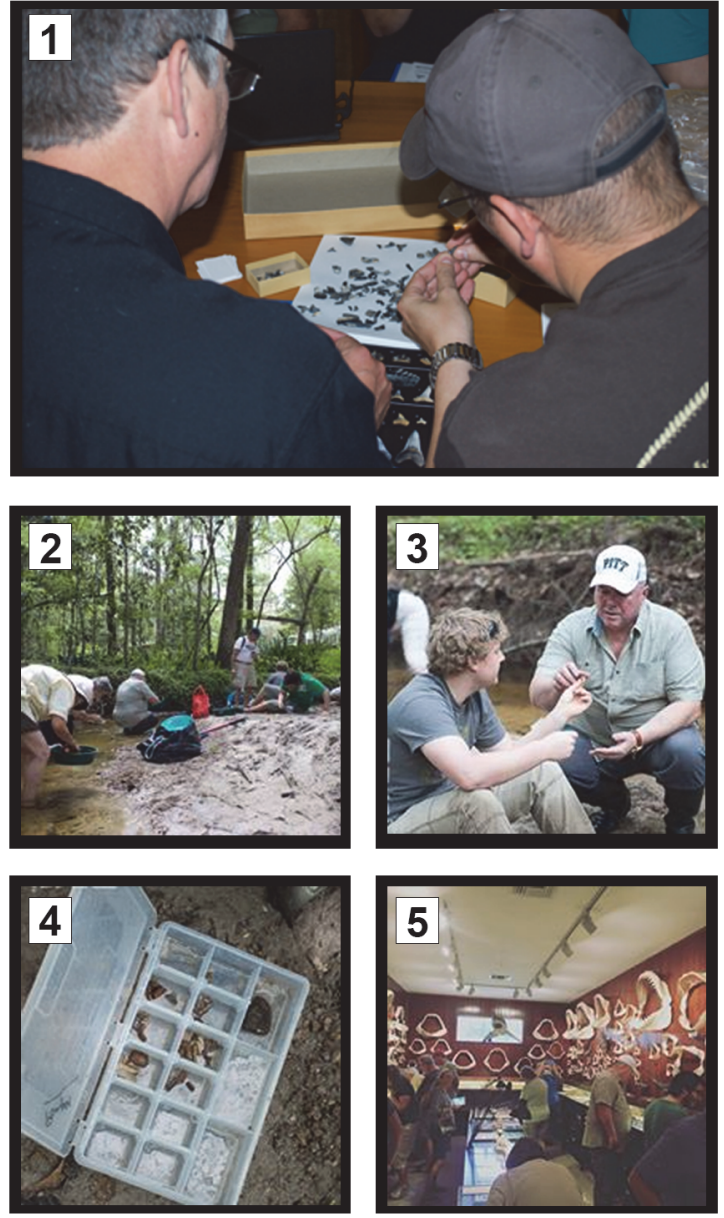

FIGURE 1. Participants engaging in the museum curation process during the PaleoBlitz: (1) participants working together to identify and catalog specimens from the Belgrade Quarry; (2) collaborative collecting in Possum Creek, Gainesville, Florida; (3) PaleoBlitz participant and FLMNH staff discussing fossil identifications; (4) field sorting specimens; and (5) experiencing curation and exhibiting practices in the Gordon Hubbell collection. Photographs by Jeff Gage.

practice of paleontology, platform for communication, and online repository for digitizing personal collections. Within the website tour, a specific focus was placed on digitization and the associated best practices of specimen photography. The myFOSSIL video tutorial guided participants through the three aspects of digitization: Pre-Digitization, Staging and Curation, and Imaging and Image Processing (http://community.myfossil.org/video-tutorials/).

To introduce the museum curatorial process, participants toured the FLMNH vertebrate paleontology and paleobotany collections. The tours highlighted the types of material catalogued in a museum collection, what information is recorded in association with each specimen, and the types of research being conducted with these specimens. With this framework in mind, the 13 participants were divided into four groups, each tasked with curating a portion of the material collected from the Belgrade Quarry (Figure 1.1). Each group was comprised of participants with different experience levels, with the specific intention of facilitating mentor-mentee relationships (i.e., a cognitive apprenticeship). The curatorial process included fossil identification, organization, documentation, and cataloging. All information was recorded in Excel spreadsheets that acted as a temporary database that could be imported into the official FLMNH vertebrate paleontology database after verification by museum staff. During this allotted time, each group had the opportunity to see the photography setup used by the museum staff, with tips on how to create do-it-yourself (DIY) versions at home. At any point in time, participants were encouraged to write down any questions or suggestions they had. These questions/comments were addressed at the conclusion of the first day in an hour-long wrap-up discussion.

On the second day, participants visited the famed Hubbell collection (Figure 1.5). Dr. Gordon Hubbell is an amateur paleontologist with one of the largest collections of fossil sharks and rays in the world. Dr. Hubbell's collection is the epitome of a well-curated amateur collection, with detailed data recorded alongside each specimen, made accessible to researchers and the public alike. Many of the exhibits are even available online for anyone to view. Following the tour of this exceptional collection, participants went on a field trip to collect fossils in local Gainesville creeks (Figure 1.2-1.4). This field trip allowed participants to put their newly acquired skills to the test. Afterwards, participants and researchers gathered to share favorite finds and help one another with identification.

\section{Research Design}

Three iterations of data collection were employed: a pre-event application (Supplemental File 1), a questionnaire immediately after the event (Supplemental File 2), and a questionnaire two months after the event (Supplemental File 3). The University of Florida Institutional Review Board approved this study, \#2016-U-99. Questions addressed the awareness and use of best paleontological practices, engagement in collaborative paleontology activities, and expectations regarding the event (Figure 2). Specific themes were derived from open-ended questions through directed con- 


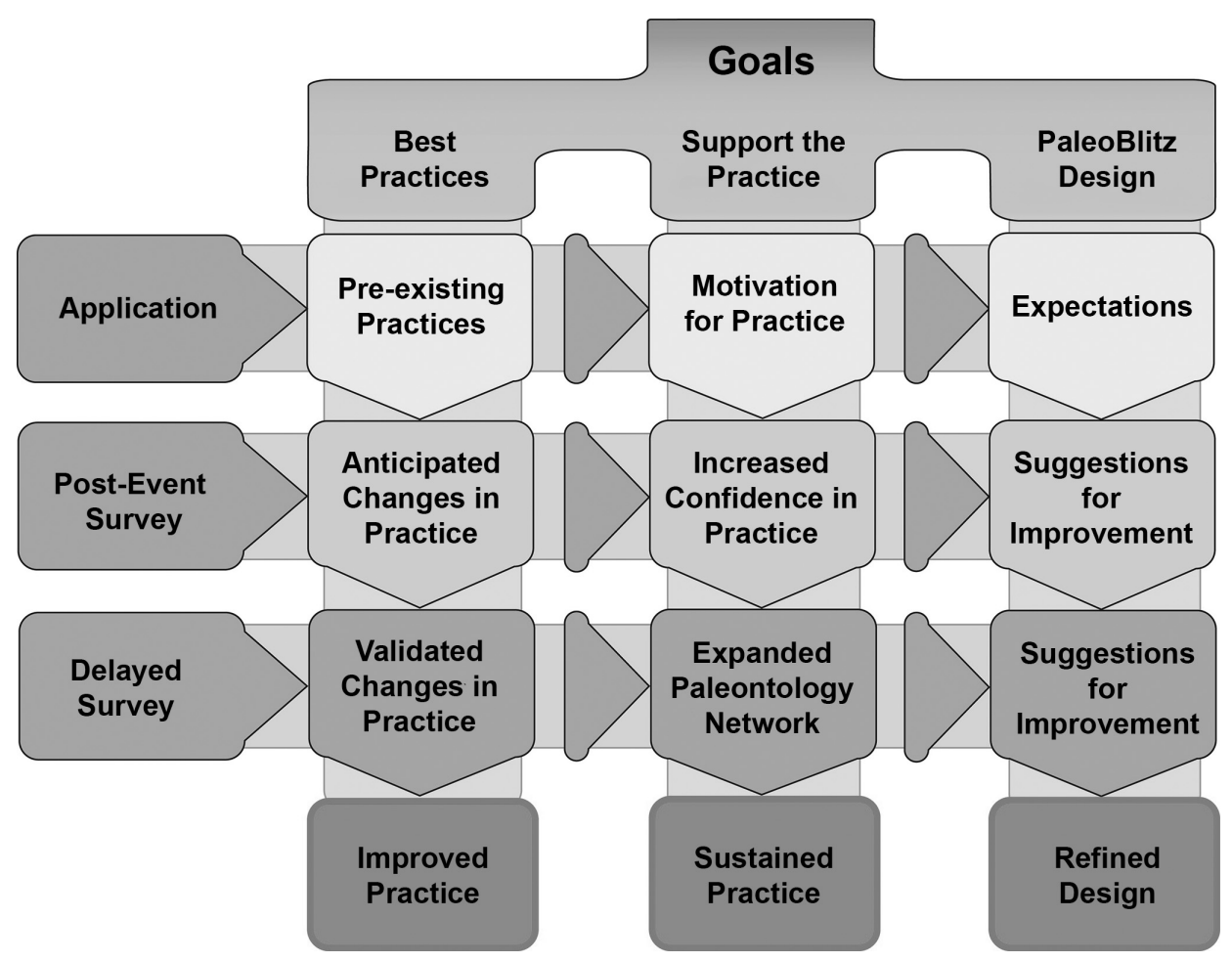

FIGURE 2. Flow chart indicating the alignment of data collection methods to the program goals. Desired outcomes are aligned to each goal: adoption of best practices throughout the museum curation process (Improved Practice); support the practice of paleontology by increasing confidence and expanding participants' personal paleontology network (Sustained Practice); and improve the structure of the PaleoBlitz through participant feedback (Refined Design).

tent analysis (Weber, 1990; Hsieh and Shannon, 2005).

The purpose of the application was to assess each individual's experience level in relation to fossil curation, motivations for practicing paleontology, and their initial expectations of the event. In total, 23 applications were received from amateurs representing at least 27 different paleontology/mineralogy organizations. Based on responses to 13 questions, we classified applicants' experience level as veteran, intermediate, or rookie. Experience level was defined by respondents' involvement in their respective paleontology organizations and self-described knowledge regarding the museum curatorial process (Table 1). We selected two representatives each from six amateur paleontology organizations to encourage collaboration within and between organizations. Pairing more involved, experienced participants (veterans) with less-involved, newer participants (rookies) served to facilitate mentor-mentee relationships (Lave and Wenger 1991; Wenger 1998, 2000; Wenger et al., 2002). Further, we selected applicants who had not participated in previous FOSSIL Project events to broaden the overall reach of the project. We ulti- mately selected 13 participants to accommodate a married couple that wanted to participate together.

Following the completion of all activities on the last day of the PaleoBlitz, participants responded to an anonymous paper-and-pencil post-event questionnaire (Supplemental File 2). The questionnaire assessed awareness of best practices in the curatorial process, self-perceived confidence towards the curatorial process, and suggestions for improving the PaleoBlitz design. Awareness of best practices was assessed by asking participants to list information that should be recorded when collecting a fossil and their likelihood to document this information in the future. Given that the paleontology curatorial process is comprised of fossil identification, preparation, curation, and documentation, the questions were divided into these categories in order to interpret each activity individually (Figure 3 ). The survey included items that asked participants to anticipate changes to their collecting and networking habits, as well as how they intend to share their newly acquired knowledge with others in the paleontology community.

Two months after the event, we sent an anonymous follow-up survey electronically to partici- 
TABLE 1. Participant Information. This table includes randomly assigned participant pseudo-names, number of years as a member of a paleontology organization, leadership positions they have held within their organization(s), frequency they attend organization events, self-perceived knowledge regarding the museum curation process, and the inferred experience level used during the applicant selection process. *Cameron responded, "Varies as to the club."

\begin{tabular}{lcllll}
\hline $\begin{array}{c}\text { Participant } \\
\text { Name }\end{array}$ & $\begin{array}{c}\text { Years in } \\
\text { Organization }\end{array}$ & $\begin{array}{c}\text { Leadership } \\
\text { Position }\end{array}$ & $\begin{array}{c}\text { Attendance } \\
\text { Frequency }\end{array}$ & Prior Knowledge & $\begin{array}{c}\text { Experience } \\
\text { Level }\end{array}$ \\
\hline Dakota & $>5$ & Vice President & All of the time & Somewhat High & Veteran \\
Elliot & $>5$ & Vice President & All of the time & Somewhat High & Veteran \\
Cameron & $>5$ & Vice President & Often* & Somewhat Low & Veteran \\
Sage & $>5$ & Field Trips & Often & Somewhat High & Veteran \\
Taylor & $>5$ & Field Trips & Sometimes & Somewhat Low & Veteran \\
Alexis & 1 to 5 & Vice President & All of the time & Very Low & Intermediate \\
Jordan & 1 to 5 & None & Often & Somewhat High & Intermediate \\
Shannon & 1 to 5 & None & Often & Somewhat Low & Intermediate \\
Sam & $>5$ & None & Often & Very Low & Intermediate \\
Rory & 1 to 5 & None & All of the time & Somewhat Low & Rookie \\
Skyler & $>5$ & None & Often & Somewhat Low & Rookie \\
Kelly & 1 to 5 & None & All of the time & Very Low & Rookie \\
Charlie & 1 to 5 & None & All of the time & Very Low & Rookie \\
\hline
\end{tabular}

pants (Supplemental File 3). This allowed participants to have time to reflect on the experience and apply what they had learned, while providing us the opportunity to determine if the participants followed through on their anticipated changes in practice described in the immediate post-event survey. At this point, we also conducted a social network analysis of the myFOSSIL online community (Hansen et al., 2010) to determine whether individuals who participated in the PaleoBlitz increased their level of engagement with others in the myFOSSIL community.

In social network analysis, a computer program shows arrangements of actors in a network, in this case the users of the myFOSSIL website. In social networking terms, users are called nodes. The arrangement of nodes is based on the nature of the connections between them. In the case of myFOSSIL, nodes are connected through the convention of friendships, where an individual chooses to connect with others (i.e., like sending a friend request on Facebook). Nodes in the network can have multiple friendships on myFOSSIL. The social media conventions for connections between nodes are called vertices. Therefore, nodes in the myFOSSIL network can have multiple vertices, with more vertices around individual nodes indicat-

\section{Participant Impact}

Please rate your level of confidence in the following activities now compared to prior to the PaleoBlitz.

$\begin{array}{llll}\text { Fossil identification } & \text { Fossil Preparation: } & \text { Fossil Curation (creating a database): } & \text { Fossil Documentation (photographing): } \\ \text { More confident } & \bigcirc \text { More confident } & \bigcirc \text { More confident } & \text { More confident } \\ \text { Somewhat confident } & \bigcirc \text { Somewhat confident } & \bigcirc \text { Somewhat confident } & \text { Somewhat confident } \\ \text { Unchanged } & \bigcirc \text { Unchanged } & \bigcirc \text { Unchanged } & \text { Unchanged } \\ \text { Somewhat less confident } & \bigcirc \text { Somewhat less confident } & \bigcirc \text { Somewhat less confident } & \text { Somewhat less confident } \\ \text { Less confident } & \bigcirc \text { Less confident } & \bigcirc \text { Less confident } & \text { Less confident }\end{array}$

FIGURE 3. Sample question from the immediate post-event questionnaire. 


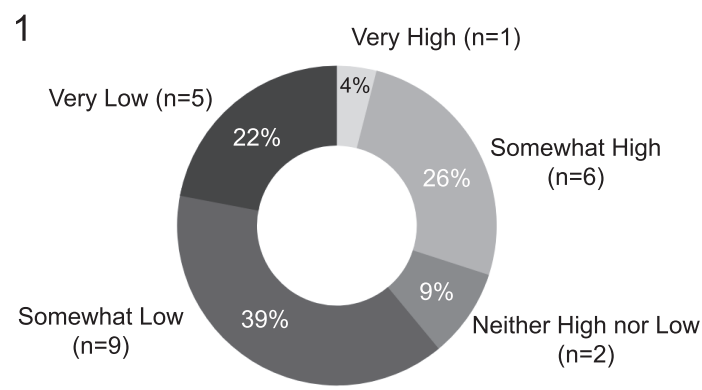

2

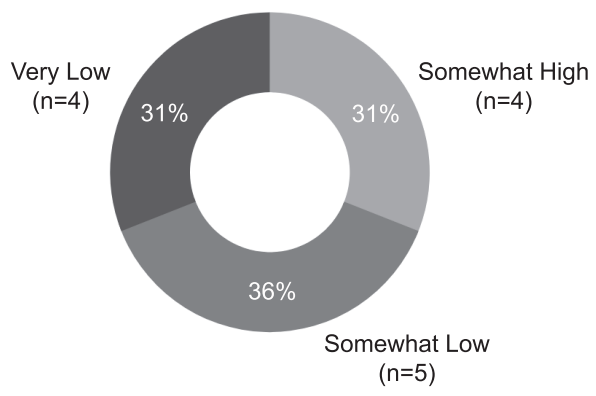

FIGURE 4. Self-perceived knowledge regarding the museum curation process, from the point a fossil enters the museum until it is recorded in a collection, prior to the PaleoBlitz. (1) responses from all applicants $(\mathrm{N}=23)$ and (2) responses from applicants selected to participate in the PaleoBlitz $(\mathrm{N}=13)$.

ing more friendships in the myFOSSIL online community.

\section{RESULTS AND DISCUSSION}

\section{Pre-event Application}

Best practices in paleontology. Among the 23 applicants, $48 \%$ had been involved in a paleontology organization for more than five years, and $43 \%$ had held an officer position at some point during their involvement. Not surprisingly, nearly every applicant was an active collector (96\%), with a single applicant that used to be an active collector. To characterize applicants' prior knowledge regarding best practices, they were asked what information they record in association with the fossils they collect. Responses ranged from no information or just taxon identifications $(22 \%)$ to more detailed records that include various types of locality data $(78 \%)$. The responses highlight the existing gradient in experience level and sophistication of organization methods applied to personal collections. The respondents' self-assigned ranking regarding their knowledge of the museum curation process further reflects this gradient (Figure 4).
Support the practice of paleontology. A multiplechoice question asking what motivates people to collect fossils also yielded a diversity of responses; but there was one shared response among all applicants-they do it for personal enjoyment (Table 2). This is to be anticipated given that the term amateur is derived from the Latin word amator, which means lover (Brown, 1954; Hooks, 2005; MacFadden et al., 2016). Thus, an amateur paleontologist is simply someone who loves paleontology, a sentiment that is well captured in this excerpt from Taylor's application: "Fossils are my passion and I spend most of my off-work hours reading about them, cleaning and restoring them or hunting for them ... [l'm] willing to go anywhere for any duration in any condition to support this effort." Motivators secondary to personal enjoyment include: for use in educational programs $(52 \%)$, for personal scientific research $(52 \%)$, to help scientists $(48 \%)$, and to support their children's interest (9\%; Table 2). Not a single applicant selected monetary gain as a motivator. However, it is possible that this is biased by the fact that the questionnaire was administered as an application to participate in an academic paleontology workshop, as it is common knowledge that the academic community generally frowns upon selling fossils. As one applicant, Taylor, wrote on their application, "I have NEVER sold a fossil. I want to ensure that if I ask to hunt on private property, that I can honestly say that."

Refine the PaleoBlitz design. The final question asked participants to explain what they wanted to gain from the PaleoBlitz, which offered further insight into motivations for participation and expectations for what the event should entail. These open-ended responses are utilized to support the results reported in Table 2. Directed content analysis (Weber, 1990) was also employed to identify specific themes, which helped to better understand applicants' expectations. The most common responses related to expanding personal knowledge for the purpose of sharing it with others $(43 \%)$; and gaining more information about fossil collecting (43\%): extraction techniques or finding new collecting localities. Simply put, this shows that people's love for collecting fossils is matched by the act of sharing that passion with others. Other common responses pertained to expanding knowledge in specific aspects of the museum curation process, as follows: fossil identification (35\%), preparation/preservation (30\%), curation (26\%), and documentation/photography (22\%). Two additional minor themes were recognized, access to collections tours and exploration of potential pale- 


\section{Perez et al.: Paleontology Citizen Science}

TABLE 2. Applicants' motivation for collecting fossils.

\begin{tabular}{|c|c|}
\hline Motivation for collecting fossils & Data Exemplars \\
\hline For personal enjoyment (100\%) & $\begin{array}{l}\text { "Finding fossils brings joy to my life. Learning about each and every } \\
\text { piece in my collection and then being able to teach people about it } \\
\text { makes me feel like I have purpose," Shannon }\end{array}$ \\
\hline Use in educational programs $(52 \%)$ & $\begin{array}{l}\text { "[PaleoBlitz participation] will help me do my volunteer job at the } \\
\text { museum better and more efficiently," Elliot } \\
\text { "I would like to expand this base knowledge and be able to pass this } \\
\text { along to others during ... educational programs," Sage }\end{array}$ \\
\hline Personal scientific research (52\%) & $\begin{array}{l}\text { "I am now a retired and can follow my early yearnings to search for } \\
\text { fossils and study geology," Rory }\end{array}$ \\
\hline To help scientists $(48 \%)$ & $\begin{array}{l}\text { "If my preservation techniques improved than my collection, current and } \\
\text { future, will potentially be more attractive/usable/scientifically important } \\
\text { to museums." Anonymous Applicant }\end{array}$ \\
\hline To support their children's interests $(9 \%)$ & $\begin{array}{l}\text { "My son has a passion for this and I have a passion for helping him } \\
\text { explore his interests as a scientist would. I think he may well study this } \\
\text { as a career and this experience for the both of us would be wonderful." } \\
\text { Anonymous Applicant }\end{array}$ \\
\hline For monetary gain $(0 \%)$ & NA \\
\hline
\end{tabular}

ontology career options (9\%, respectively; Table $3)$.

The challenge of the Blitz concept, which is by definition a short-term event, is meeting the participants' wide range of desired outcomes in a brief amount of time. As such, the goal of the PaleoBlitz was to provide a rapid immersion into the entire museum curatorial process; and in doing so, accommodate the desired outcomes of all applicants. Even though the aspect of preparation and preservation was one of the most popular themes, its inclusion during the PaleoBlitz was essentially limited to discussion, as opposed to hands on practice, given the brevity of the event and the complexity of the topic.

\section{Post-event Survey}

Best practices in paleontology. Participants were asked to list at least three kinds of information that should be recorded when collecting a fossil and to explain why they would or would not record this information. Throughout the entire event, one of the most crucial points repeatedly stated was the importance of recording locality data. While only one participant listed less than three types of data, all participants wrote down locality data as a necessary piece of information. When asked to elaborate why one would or would not record this information, all but two participants explained why they would record the information. The two anonymous participants that explained why they would not record the information gave the following rationales, "When the item is fragmented/common," and "Would not write explanation if there wasn't enough time." These quotes include two explanations for why one might not record this information: if the fossil was common or poorly preserved and lack of time. Lack of time probably is not a sufficient reason to refrain from recording information, but not curating common or poorly preserved specimens is a reasonable practice that is also employed in museum collections. However, it is important to keep in mind that there are instances when curating common or poorly preserved specimens is necessary. For example, in order to document the biodiversity of an area, researchers must evenly sample everything; which means recording every fossil occurrence, even if it is common or poorly preserved.

Supporting the practice of paleontology. The immediate post-event survey sought to determine changes in self-perceived confidence related to the museum curation process after participation in the PaleoBlitz. Respondents ranked their confidence on a five-point scale from less confident to more confident for the following practices: fossil identification, preparation, documentation, and curation, respectively (Figure 5).

Identification was primarily addressed at two points: while curating the Belgrade material and briefly after collecting in the Gainesville creeks. Supplied resources and interactions with museum staff aided these identifications. In both cases, material was predominantly marine fossils (mostly shark teeth) of Cenozoic age. From the application, all but two of the participants indicated that they had collected in areas that have comparable fossils to those from Belgrade and Gainesville in the past. 
TABLE 3. Specific themes related to applicants' expectations and desired outcomes identified through directed content analysis of the PaleoBlitz application questionnaire.

\begin{tabular}{|c|c|}
\hline Desired Outcomes & Data Exemplars \\
\hline Fossil collecting (43\%) & $\begin{array}{l}\text { "I am interested in learning best practices as a collector," Jordan } \\
\text { "gain more and new techniques for fossil collecting, data collection, ..., , Anonymous } \\
\text { Applicant } \\
\text { "... get info about collecting ..., , Anonymous Applicant }\end{array}$ \\
\hline Fossil identification (35\%) & $\begin{array}{l}\text { "increase my knowledge of ... classification methods," Skyler } \\
\text { "I hope to be able to identify more fossils in the future, I would like to be able to id fossils } \\
\text { better in the field," Kelly } \\
\text { "... be able to identify my own fossils," Charlie }\end{array}$ \\
\hline Fossil Preparation (30\%) & $\begin{array}{l}\text { "I would like to increase my knowledge of fossil preservation," Skyler } \\
\text { "I would hope to gain additional knowledge of the fossil preservation process (the entire } \\
\text { process) and especially preparation/preservation of specific specimen," Anonymous } \\
\text { Applicant }\end{array}$ \\
\hline Cataloging Fossils (26\%) & $\begin{array}{l}\text { "I would like to learn curation techniques with large collections to improve my } \\
\text { methodology with my collection," Cameron } \\
\text { "The PaleoBlitz would give me a better understanding of the process of fossil curation," } \\
\text { Alexis } \\
\text { "Gain knowledge of how to label new finds," Sam } \\
\text { "I'm trying to annotate my fossil collection," Dakota }\end{array}$ \\
\hline Fossil documentation (22\%) & $\begin{array}{l}\text { "I am missing large sections of knowledge and experience in the extraction, preparation, } \\
\text { documentation and curation of specimens," Taylor } \\
\text { "Additional information in the curation and photography of fossils," Anonymous Applicant } \\
\text { "... knowledge of new electronic techniques," Anonymous Applicant }\end{array}$ \\
\hline Museum tours $(9 \%)$ & $\begin{array}{l}\text { "see the collections at FLNMH," Anonymous Applicant } \\
\text { "visit with Dr. Hubbell ... museum," Anonymous Applicant }\end{array}$ \\
\hline Paleontology Careers (9\%) & $\begin{array}{l}\text { "I would like to gain a better understanding of what kind of careers one can have in the } \\
\text { field," Anonymous Applicant } \\
\text { "My son has a passion for this and I have a passion for helping him explore his interests } \\
\text { as a scientist would. I think he may well study this as a career and this experience for the } \\
\text { both of us would be wonderful," Anonymous Applicant }\end{array}$ \\
\hline
\end{tabular}

Thus, many of the more experienced participants, particularly those along the east coast of the United States, probably would have felt that they already knew how to identify the fossils utilized during the PaleoBlitz. Regardless, $38 \%$ of the participants felt more confident in their identification skills after the PaleoBlitz.

Preparation of fossils came up in discussion often during the PaleoBlitz; and yet, despite being an important part of the event, participants did not actually get first-hand experience with the practice of fossil preparation. During the collections tour, participants visited the Prep Lab in the vertebrate paleontology range, in which they were able to see fossils at different stages in the preparation process and many of the common tools employed. However, essentially all the material collected from the Belgrade Quarry required little to no cleaning or repair. Further, the timeframe did not allot for any extensive fossil preparation/preservation training. Even so, from the tour and discussion alone, $46 \%$ felt more confident with fossil preparation after the PaleoBlitz. One participant even went as far to say, "I felt preparation was the most meaningful."
Documentation, aka digitization or photography, has become increasingly important in this digital age, which further justifies the need for a wellestablished set of best practices. The myFOSSIL website serves as a platform to do this in a structured and organized way, while providing tutorials on proper techniques and DIY tips. During the PaleoBlitz, the FOSSIL digitization tutorial was shown as an example of the resources available on the myFOSSIL website, and all participants were given a tour of the photography setup used in the vertebrate paleontology range at FLMNH. Consequently, $69 \%$ of the participants felt more confident with fossil documentation after the PaleoBlitz.

Curation was by far the biggest component of the PaleoBlitz, given that organization of specimens and associated data is debatably the most important stage in the entire curatorial process. Recording locality information, with as much detail as possible, is essential to progressing the field of paleontology. In order to highlight this importance, participants were repeatedly exposed to organizational techniques and the kinds of data that are typically recorded with a catalogued specimen. Within 


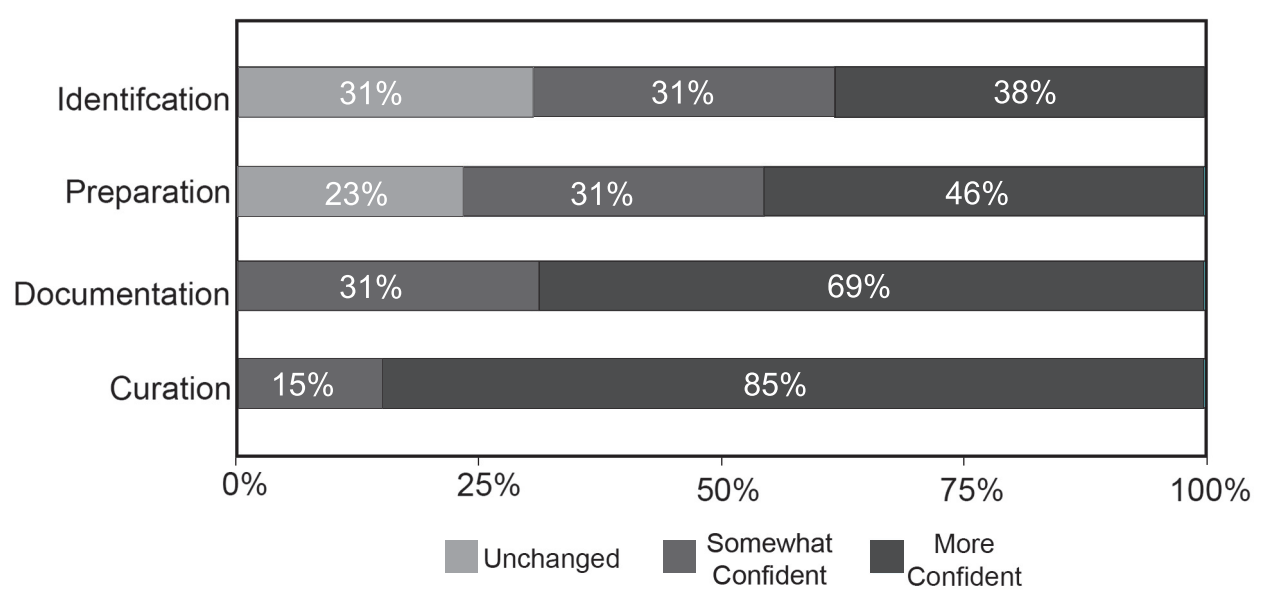

FIGURE 5. Self-perceived confidence in specific aspects of the museum curation process after participation in the PaleoBlitz.

the myFOSSIL website, when a fossil is uploaded, subfields request associated data. During the museum tour, participants were shown how specimens are organized by age of the site, site name, and then by fossil identification. Further, every specimen has a card with a catalog number, taxon name, site name, collector name, and collection date. The main activity on the first day was to emulate this by curating the fossils from Belgrade, during which each group was given an Excel spreadsheet that already contained the necessary column headings to ensure that all pertinent data was recorded. On the second day, participants visited the Hubbell collection and saw a well-organized private collection. Consequently, with such a significant focus placed on curation, $85 \%$ of participants felt more confident and $15 \%$ felt somewhat more confident after participation.

Responses from this survey also aimed to determine whether participants anticipated changes in their paleontological practices or personal paleontology networks. Participants were asked how likely they would be to include associated data with future collections and how likely they would be to make changes to their existing collections. All participants chose either very likely (85\%) or likely $(15 \%)$ to include associated data with future fossil collections. One applicant supported that choice with the following statement: "As far as I'm concerned, if you don't know at least the location and age of a fossil, it's not worth owning." Given that the sophistication of organization in existing personal collections was highly variable, we anticipated that not everyone would make changes, or at least would not make changes to the same degree. Overall, $54 \%$ said they were very likely to make changes, $31 \%$ said they were likely, $8 \%$ chose undecided, and $8 \%$ said they were unlikely to make changes. For the two applicants that did not say they were likely to make changes, one already has a database in which their personal collection is curated, and the other was unsure if they would be able to retroactively find the information to re-organize their collection. Both justifications are reasonable for why one may not make changes to their existing collection.

Participants were asked if they anticipated any new collaborations as a result of the PaleoBlitz, changes in involvement with other amateurs and professionals, as well as their plans for sharing what they have learned with others (which was an expectation of all participants). All participants felt they were either very likely $(69 \%)$ or likely $(31 \%)$ to make a new collaboration as a result of the PaleoBlitz. Anticipated changes in involvement with others varied because a few felt they already were adequately involved, while others anticipated changes because they felt more confident in becoming an informative resource for others in their respective organizations. Participants indicated a few different ways they intended to share their newly acquired skills with others. Most intended to bring what they learned back to their respective clubs via workshops and/or newsletter articles that shared their experience. "We plan to give a program on the PaleoBlitz program to our club." Others stated they would incorporate what they had learned in education and outreach programs or into their volunteer work at various museums. "I plan to do programs at elementary schools 
TABLE 4. Outcomes of the PaleoBlitz. All quotes are anonymous.

\begin{tabular}{ll}
\hline \multicolumn{1}{c}{ Outcomes } & \multicolumn{1}{c}{ Data Exemplar } \\
\hline Changes to existing collections (100\%) & $\begin{array}{l}\text { "I have taken another look at my existing displays and have attempted to } \\
\text { identify some fossils that I was unsure of. I intend to photograph the fossils } \\
\text { once I have more time." } \\
\text { "Earlier I was guilty of gathering information for documentation well after } \\
\text { the collection trip. Now I am much more aware that this info (location, etc.) } \\
\text { is much easier to get and should be obtained while at the location." } \\
\text { "I have shared matrix and fossils with participants from the PaleoBlitz. I } \\
\text { also have planned trips and have offered participation on trips I am } \\
\text { planning. I will maintain these relationships." } \\
\text { "I have discussed what I have learned with other fossil enthusiasts. I am } \\
\text { also inspired to start publishing help videos and instructions and } \\
\text { participate closer with my local museums and universities." }\end{array}$ \\
\hline
\end{tabular}

and can help explain how museums curate the fossils."

Refining the PaleoBlitz design. The last goal of the post-event survey was to receive feedback that would improve the PaleoBlitz design. There was a unanimous sentiment that the PaleoBlitz workshop was a worthwhile experience, and that the skills and knowledge acquired were immediately applicable. All but one participant agreed that time was appropriately distributed among the various activities. However, all participants indicated that they would have liked more time on one activity or another, with many requesting a greater focus on fossil preparation and/or time spent collecting. This request can only be accommodated through the implementation of additional events similar to that of the PaleoBlitz that focus on education of the museum curation process, either generally or specific to individual aspects of the entire process.

\section{Delayed Survey}

Best practices in paleontology. As noted above, immediately following the PaleoBlitz $85 \%$ of participants indicated they planned to make changes to their existing collections; however, two months later every participant reported making changes to their existing collections (Table 4). Participants made changes at all stages of the museum curatorial process, with the biggest impact being on the documentation of existing collections (Figure 6). Every participant went collecting since the PaleoBlitz and many $(77 \%)$ also reported changes to their collecting habits, primarily in reference to recording field data and documenting their finds (Table 4).

Supporting the practice of paleontology. Nearly every participant $(92 \%)$ reported staying in contact with at least one other participant from the PaleoBlitz. Interactions included going on collect- ing trips together, sharing collecting localities, exchanging fossil material, helping each other with fossil identifications, and general discussions about paleontology. A majority of the participants $(85 \%)$ reported that they had either completed or had a scheduled event, in which they shared what they learned at the PaleoBlitz with others (Table 4). Tangible outputs included newsletter articles $(46 \%)$, presentations $(23 \%)$, workshops $(15 \%)$, and leading field trips (15\%) (Figure 7).

Refining the PaleoBlitz design. Two months following the PaleoBlitz, all participants still reported that they would have appreciated more time on at least one of the blitz components. Some simply wanted the event to be longer, with more time spent either on field and/or lab techniques. Given that a blitz is a rapid event, it should result in the participants wanting more. You simply cannot teach everyone everything in two days; however, you can provide adequate information and resources so that individuals can pursue specific

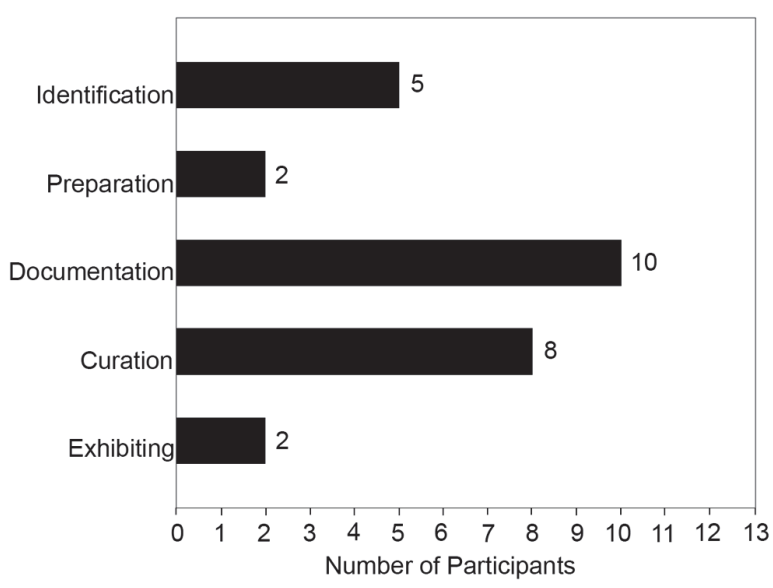

FIGURE 6. Changes made by participants to their existing collections two months after the PaleoBlitz. 


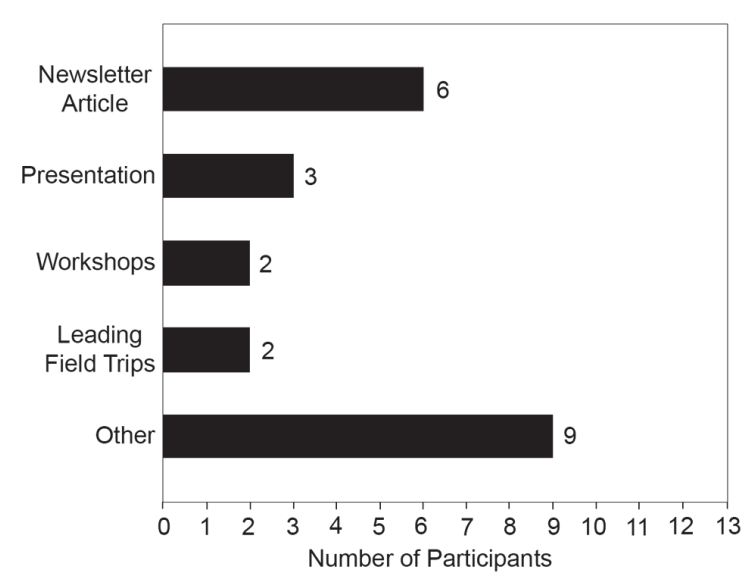

FIGURE 7. Participants' deliverables two months after the PaleoBlitz.

aspects in greater depth independently. Others had very insightful suggestions on re-structuring the design. Two suggestions in particular were striking:

Have the group first locate the fossils from the site, then guide the participants through the extraction, preparation, curation, and identification process using any available lab equipment or resources. But pick a site that has a variety of fossils (family and species) from a specific time epoch, and encourage the participants to collect the variety, so they can eventually describe the site as it was during the specific time. The program leaders should recommend resources that would make the identification process more accurate. End the program by having the participants build the collection database, and write a description of the site, as it might have been, during the specific time, based on the identified fossils. In other words, write a plausible story of 'one day in the life' of the specific geologic time and place.

Anonymous Participant

I would like to have a quick introduction to an assortment of sites/time periods. Maybe this could even be part of the introductions on the first day. Each participant, if they want, could do five minutes or less on one of their favorite sites telling about its geology and fossils as part of their own introduction.

Anonymous Participant
The first suggested that the event begin with participants collecting and that all proceeding activities build upon those fossils, ending with participants creating a database of these fossils and writing a description of the fossil site. This would provide participants with their own individual databases from which they could build upon independently. The second suggestion was to begin the event with an overview of a number of different fossil sites of different geologic ages. The Belgrade PaleoBlitz was very Cenozoic-centric; however, participants came from all over the United States, with personal collections from numerous different geologic time periods. The suggestion was that each participant provide a five-minute overview of their favorite collecting site and integrate this into the introductions, which would aid in exemplifying the diversity of collecting and preparation strategies associated with different kinds of fossils.

\section{Social Network Analysis}

The social network graph (Figure 8) shows the community of people on the myFOSSIL website $(\mathrm{N}=197)$ as of May 7,2016 . Three different colored nodes (blue triangles, orange circles, and pink squares) represent different categories of myFOSSIL membership. The blue triangles represent FOSSIL Project staff members $(n=8)$. Orange circles are myFOSSIL members who participated in the March 2016 PaleoBlitz $(n=13)$. Pink squares represent all other myFOSSIL members $(n=176)$. The FOSSIL Project leadership team, or core nodes, is the most connected to peripheral nodes as represented by the scattering of vertices radiating outward from the blue triangles. As seen in Figure 8.1, the FOSSIL Project team is at the core of the myFOSSIL social network. In the social paleontology community of practice, the generational structure of knowledge has not yet been fully established (Wenger, 1998). Current practices and relationships are embodied in the direct connections between FOSSIL Project leadership and some myFOSSIL members; however, with the FOSSIL Project team in the analysis, it could not be determined if community members have taken on leadership or core roles themselves.

In order to test this assumption, the FOSSIL Project leadership core was removed from analysis (Figure 8.2). Without the FOSSIL Project team, many of the vertices between nodes disappear. The most vertices exist between nodes who participated in one of the FOSSIL Project's face-to-face events, such as the PaleoBlitz. These nodes have, on average, 7.9 connections, whereas the average 


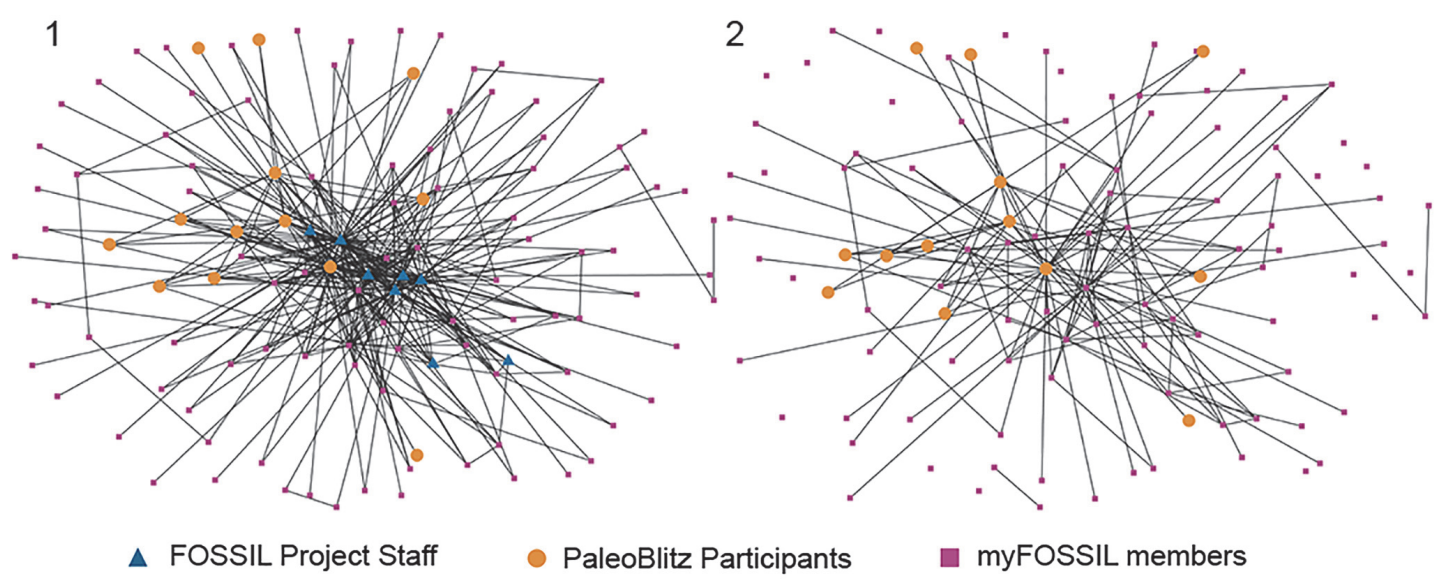

FIGURE 8. Social network graphs of myFOSSIL. (1) friendships on myFOSSIL.org with the FOSSIL Project staff (blue triangles), PaleoBlitz participants (orange circles), and myFOSSIL members (purple squares). (2) Friendships on myFOSSIL.org between PaleoBlitz participants and myFOSSIL members, without the FOSSIL Project staff. Created on NodeXL Pro (http://nodexl.codeplex.com) from the Social Media Research Foundation (http://www.smrfoundation.org).

myFOSSIL member has 5.5 connections. Relationships that have been developed in real time and face-to-face are currently more connected and more likely to be represented in the myFOSSIL community than those developed through the myFOSSIL website alone. The social fabric of the myFOSSIL website is currently determined by connections within the core and connections made via face-to-face interactions. The PaleoBlitz helped to facilitate new connections between amateur paleontologists, which then can be fostered through additional interactions on the myFOSSIL community site.

\section{CONCLUSION}

The classic concept of a "Blitz" is a rapid effort to make significant contributions to science. Originally, this pertained mostly to capturing biodiversity of extant organisms in a specific area but has since evolved to include paleontology and other stages of the curatorial process. Secondary to the scientific value of these events is often the education of the participants. Participants inevitably gain knowledge through first-hand exposure to professional techniques and tools; however, these events typically lack a structured educational design. In contrast, the primary objective of the Belgrade PaleoBlitz was the education of the participants in the entire museum curatorial process, so that they could replicate this process in their own personal collections. Secondary to this educational goal was the curation of fossils that had been collected from the Belgrade Quarry. This idea pertains to the well- known proverb, "Give a man a fish and you feed him for a day; teach a man to fish and you feed him for a lifetime." As is the case in other natural history fields, paleontology has a large, dedicated amateur community of practitioners. Educating these individuals in the best practices and providing platforms for collaboration will lead to a much more significant impact in the long run than if the main goal of this event was simply to catalog the fossils from Belgrade.

The Belgrade PaleoBlitz was a rapid immersion into the entire museum curatorial process; and not surprisingly, this left most participants wanting more. Undoubtedly, in any educational effort participants will have a variety of backgrounds with some having more experience than others do. Consequently, the impact will not be uniform among all participants and individuals will want expansion on different aspects. No single event can encompass the entirety of these desired outcomes, especially not in the duration of a one or two-day event. Nor can any single event facilitate everyone that would like to participate. The solution to this is two-fold: 1) events can be designed to broadly cover the entire process, as the PaleoBlitz aimed to do, or they can be designed as more in depth, specialty workshops that focus on single aspects, such as preparation or digitization; and 2) provide participants with the skills and tools to implement these workshops themselves. By making education the focus of these events, participants will leave with greater confidence to share this knowledge with others, resulting in a greater range of dissemination and overall impact. 


\section{ACKNOWLEDGEMENTS}

We would like to thank everyone that applied to participate in this event. We would also like to thank E. Gardner, S. Moran, and B. MacFadden for their help hosting the PaleoBlitz, as well as J. Gage for documenting the event. Finally, the authors give a huge thank you to $G$. Hubbell for allowing us to visit his personal collection. This project was sup- ported by NSF under Grant No. DGE-1315138, DGE-1842473, and DRL-1322725. Any opinions, findings, and conclusions or recommendations expressed in this material are those of the author(s) and do not necessarily reflect the views of the National Science Foundation. This manuscript is the University of Florida Contribution to Paleobiology number 864 .

\section{REFERENCES}

Bixby, S. 2014. Stopping the million-dollar fossil thieves: illegal trade meets world of insatiable research. The Daily Beast. 11 June 2014. https://www.thedailybeast.com/stopping-themillion-dollar-fossil-thieves-illegal-trade-meets-world-of-insatiable-research

Boyd, B.M. 2016. Fossil sharks and rays of Gainesville creeks Alachua County, Florida: Hawthorne Group (middle Miocene to lower Pliocene). Florida Paleontological Society Special Papers, p. 1-40.

Brown, R.W. 1954. The Composition of Scientific Words. Smithsonian Institution Press, Washington, D.C.

Collins, A. 2006. Cognitive Apprenticeship, p. 47-60. In Sawyer, R.K. (ed.), The Cambridge Handbook of the Learning Sciences. Cambridge University Press, New York.

Crippen, K.J., Ellis, S., Dunckel, B.A., Hendy, A.J.W., and MacFadden, B.J. 2016. Seeking shared practice: A juxtaposition of the attributes and activities of organized fossil groups with those of professional paleontology. Journal of Science Education and Technology, 25(5):731-746. https://doi.org/10.1007/s10956-016-9627-3

Godfrey, S.J. 2015. Snaggletooth shark on display. The Ecphora Newsletter, 30(3):3.

Hansen, D., Shneiderman, B., and Smith, M.K. 2010. Analyzing Social Media Networks with NodeXL. Morgan Kaufmann, Burlington.

Hooks, G.E., III. 2005. The importance of the amateur paleontologist, p. 187-188. In Buta, R.J., Rindsberg, A.K., and Kopaska-Merkel, D.C. (eds.), Pennsylvanian Footprints in the Black Warrior Basin of Alabama. Alabama Paleontological Society Monograph, Birmingham, no. 1.

Hsieh, H.-F. and Shannon, S.E. 2005. Three approaches to qualitative content analysis. Qualitative Health Research, 15(9):1277-1288. https://doi.org/10.1177/1049732305276687

Kallmeyer, J.W. and Ausich, W.I. 2015. Deepwater occurrence of a new Glyptocrinus (Crinoidea, Camerata) from the Late Ordovician of southwestern Ohio and northern Kentucky: revision of crinoid paleocommunity composition. Journal of Paleontology, 89(6):1068-1075. https:// doi.org/10.1017/jpa.2015.72

Karns, D.R., Ruch, D.D., Brodman, R.D., Jackson, M.T., Rothrock, P.E., Scott, P.E., Simon, T.P., and Whitaker Jr, J.O. 2006. Results of a short-term BioBlitz of the aquatic and terrestrial habitats of Otter Creek, Vigo County, Indiana. Proceedings of the Indiana Academy of Science, 115(2):82-88.

Lave, J. and Wenger, E. 1991. Situated Learning: Legitimate Peripheral Participation. Cambridge University Press, New York.

Lundmark, C. 2003. BioBlitz: getting into backyard biodiversity. Bioscience, 53(4):329-329. https://doi.org/10.1641/0006-3568(2003)053[0329:BGIBB]2.0.CO;2

MacFadden, B.J., Lundgren, L.M., Crippen, K.J., Dunckel, B., and Ellis, S. 2016. Amateur paleontological societies and fossil clubs, interactions with professional paleontologists, and the rise of 21 st century social paleontology in the United States. Palaeontologia Electronica 19.2.1E:1-19. https://doi.org/10.26879/161E. palaeo-electronica.org/content/2016/1471-commentary-amateur-professionals-in-us

Pugh, A.C., Danise, S., Brown, J.R., and Twitchett, R.J. 2015. Benthic ecosystem dynamics following the Late Triassic mass extinction event: palaeoecology of the Blue Lias Formation, Lyme Regis, UK. Geoscience in South-West England, 13:255-266. 
Richards, H.G. 1950. Geology of the coastal plain of North Carolina. Transactions of the American Philosophical Society, 40(1):1-83.

Robbins, J. 2009. Instead of glory, the finder of a rare dinosaur fossil faces charges of theft. New York Times. 21 January 2009. https://www.nytimes.com/2009/01/22/us/22fossil.html

Santucci, V.L., Tweet, J.S., and Kenworthy, J.P. 2012. Paleoblitz: Uncovering the fossil record of the national parks. Park Science, 29(1):29-32.

Twitchett, R.J. 2015. FossilBlitz. The Paleontology Newsletter, 90(4):54-56.

Twitchett, R.J., Bowman, V.C., Crame, J.A., Dunhill, A.M., Foster, W.J., Little, C.T.S., McGowan, A.J., Pugh, A.C., and Witts, J.D. 2015. FOSSILBLITZ! Extending the BioBlitz concept to deep time. Geological Society of America Abstracts with Programs, 47(7):113.

United States Geological Survey, 1996. Kenilworth Park and Aquatic Gardens - BioBlitz, Patuxent Wildlife Research Center. http://www.pwrc.usgs.gov/blitz/kenilw.html

Weber, R. 1990. Basis Content Analysis (second edition). Sage Publications, Thousand Oaks.

Wenger, E. 1998. Communities of Practice: Learning, Meaning, and Identity. Cambridge University Press, Cambridge.

Wenger, E. 2000. Communities of Practice and Social Learning Systems. Organization, 7(2):225-246. https://doi.org/10.1177/135050840072002

Wenger, E., McDermott, R.A., and Snyder, W. 2002. Cultivating Communities of Practice. Harvard Business School Press, Boston. 


\section{SUPPLEMENTAL MATERIAL}

Supplemental File 1. Pre-event application disseminated to the amateur paleontology.

Supplemental File 2. Post-PaleoBlitz questionnaire completed by participants at the end of the PaleoBlitz event.

Supplemental File 3. Delayed questionnaire sent to participants two months after the PaleoBlitz event.

This material is available in a zipped file at https://palaeo-electronica.org/content/2020/3009paleontology-citizen-science 